Article

\title{
The Prediction of Gestational Hypertension, Preeclampsia and Fetal Growth Restriction via the First Trimester Screening of Plasma Exosomal C19MC microRNAs
}

\author{
Ilona Hromadnikova ${ }^{1, * \mathbb{C}}$, Lenka Dvorakova ${ }^{1}$, Katerina Kotlabova ${ }^{1}$ and Ladislav Krofta ${ }^{2}$ \\ 1 Department of Molecular Biology and Cell Pathology, Third Faculty of Medicine, Charles University, \\ 10000 Prague, Czech Republic; lenka.dvorakova@lf3.cuni.cz (L.D.); katerina.kotlabova@lf3.cuni.cz (K.K.) \\ 2 Institute for the Care of the Mother and Child, Third Faculty of Medicine, Charles University, \\ 14700 Prague, Czech Republic; ladislav.krofta@upmd.eu \\ * Correspondence: ilona.hromadnikova@lf3.cuni.cz; Tel.: +420-296-511-336
}

Received: 29 March 2019; Accepted: 15 June 2019; Published: 18 June 2019

\begin{abstract}
The aim of the study was to verify if quantification of placental specific C19MC microRNAs in plasma exosomes would be able to differentiate during the early stages of gestation between patients subsequently developing pregnancy-related complications and women with the normal course of gestation and if this differentiation would lead to the improvement of the diagnostical potential. The retrospective study on singleton Caucasian pregnancies was performed within 6/2011-2/2019. The case control study, nested in a cohort, involved women that later developed GH $(n=57)$, PE $(n=43)$, FGR $(n=63)$, and 102 controls. Maternal plasma exosome profiling was performed with the selection of C19MC microRNAs with diagnostical potential only (miR-516b-5p, miR-517-5p, miR-518b, miR-520a-5p, miR-520h, and miR-525-5p) using real-time RT-PCR. The down-regulation of miR-517-5p, miR-520a-5p, and miR-525-5p was observed in patients with later occurrence of GH and PE. Maternal plasma exosomal profiling of selected C19MC microRNAs also revealed a novel down-regulated biomarker during the first trimester of gestation (miR-520a-5p) for women destinated to develop FGR. First trimester circulating plasma exosomes possess the identical C19MC microRNA expression profile as placental tissues derived from patients with GH, PE and FGR after labor. The predictive accuracy of first trimester C19MC microRNA screening (miR-517-5p, miR-520a-5p, and miR-525-5p) for the diagnosis of GH and PE was significantly higher in the case of expression profiling of maternal plasma exosomes compared to expression profiling of the whole maternal plasma samples.
\end{abstract}

Keywords: C19MC microRNA; expression; exosomes; fetal growth restriction; gestational hypertension; plasma; prediction; preeclampsia; pregnancy-related complications; screening

\section{Introduction}

Most previous studies performed C19MC microRNA profiling analyses on whole maternal plasma or serum samples with the aim to diagnose or predict the later occurrence of pregnancy-related complications [1-10]. Nevertheless, nowadays with regard to the perspectives of potential usage of exosomes as therapeutics in placental-mediated disorders [11-14], it is crucial to characterize first the inner content of placental derived exosomes, and next to describe their impact on the modulation of maternal immune system and metabolism through the mediation of distant cell-cell communication [11].

Exosomes are small size vesicles $(30-150 \mathrm{~nm})$ of the endosomal origin released to the extracellular space by most cells including trophoblast cells that mediate cell-cell communication through signaling 
molecules (proteins, lipids, RNA, and DNA) released after the exocytosis fusion of multi-vesicular body with the cell membrane of the target cell [11,15-23].

C19MC microRNAs represent unique placental specific biomarkers to be tested in plasma/serum exosomes during gestation, since only paternally inherited alleles are expressed in the placenta due to genomic imprinting [24]. Nevertheless, since some microRNAs from C19MC microRNA cluster were demonstrated to be also expressed in the testis, embryonic stem cells, and specific tumors [25-28], we previously selected, from the C19MC microRNA cluster, only those microRNAs (miR-516-5p, miR-517-5p, miR-518b, miR-520a-5p, miR-520h, and miR-525-5p) that were exclusively or abundantly expressed in the placenta, showed minimal expression in other tissues and maximum diagnostical potential $(100 \%$ detection rate in maternal plasma samples throughout gestation, from early stages to term pregnancy) $[3,29,30]$.

To date, little data on first trimester exosome microRNA profiling is available in women with subsequent development of pregnancy-related complications such as gestational hypertension (GH), preeclampsia (PE), and/or fetal growth restriction (FGR) [22,31].

This study is a follow-up of our previous studies dedicated to first trimester screening of circulating C19MC microRNAs in whole maternal plasma and its potential to predict subsequent onset of gestational hypertension, preeclampsia, and/or FGR [6,9]. The aims of the current study are to explore A) if quantification of placental specific C19MC microRNAs in plasma exosomes would be able to differentiate during the early stages of gestation between patients subsequently developing pregnancy-related complications and women with normal course of gestation and B) if this differentiation would lead to the improvement of their diagnostical potential (better detection rate).

\section{Results}

Gene expression of C19MC microRNAs in plasma exosomes was retrospectively compared between women with normal and complicated course of gestation (GH, PE, and FGR) within 10 to 13 weeks. Just the results that reached a statistical significance or displayed a trend toward aberrant levels of circulating C19MC microRNAs in complicated cases are presented below.

\subsection{Plasma Exosomal miR-517-5p, miR-520a-5p and miR-525-5p are Down-Regulated during the First Trimester of Gestation in Women Affected with GH and PE}

The expression profile of miR-517-5p, miR-520a-5p, and miR-525-5p differed significantly or showed a trend toward statistical significance between the groups of women with later onset of GH or PE and the controls. Decreased levels of miR-517-5p, miR-520a-5p, and miR-525-5p were detected during the first trimester of gestation in circulating plasma exosomes in women that later developed either GH or PE (Figure 1).

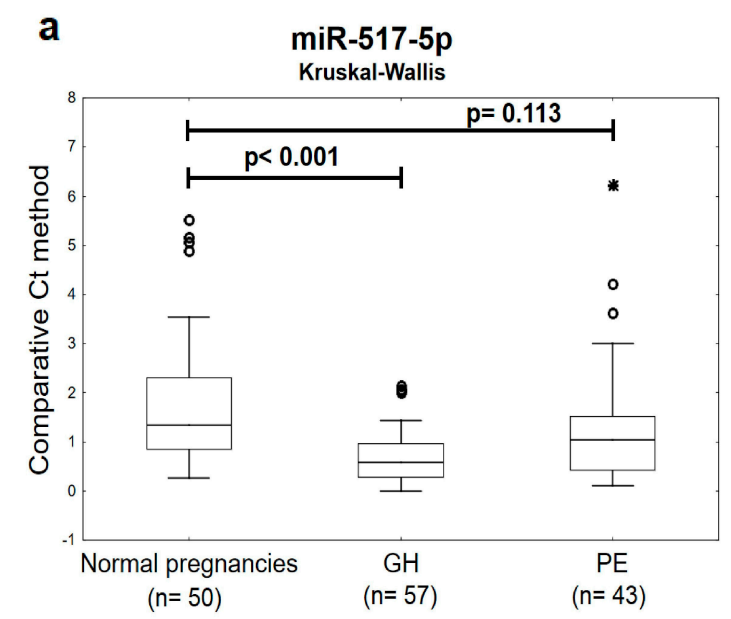

Figure 1. Cont. 

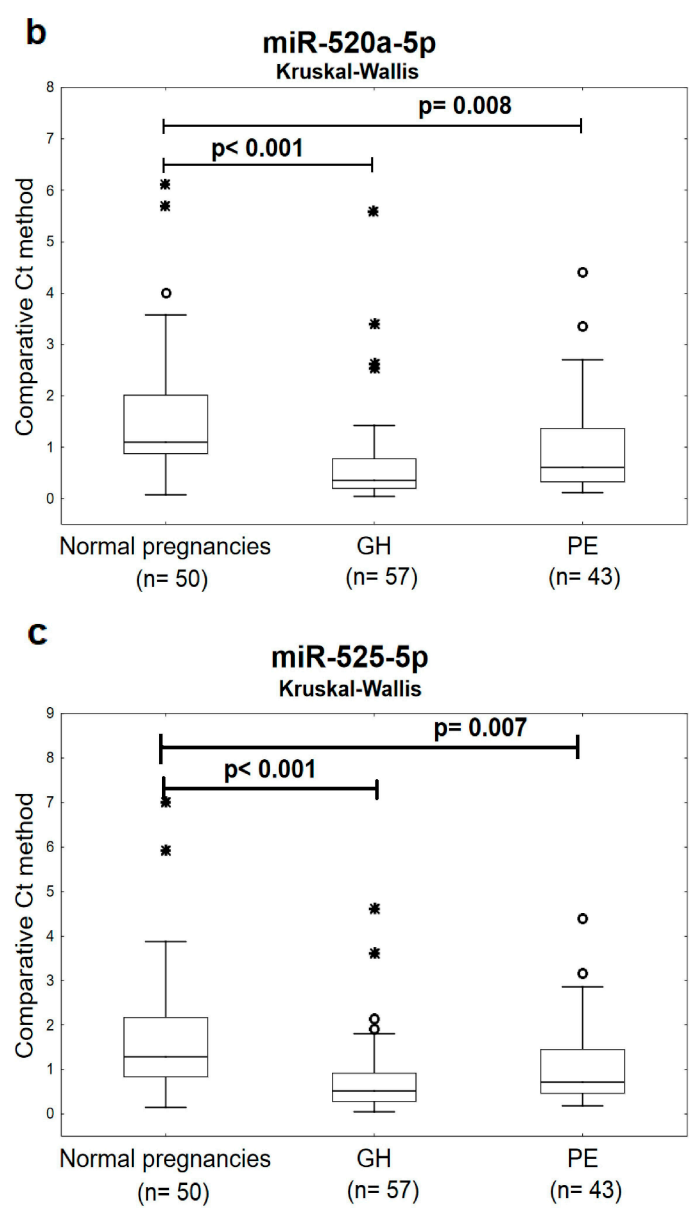

Figure 1. Down-regulation of miR-517-5p, miR-520a-5p, and miR-525-5p in plasma exosomes during the first trimester of gestation in women with later onset of GH or PE.(a-c) Decreased levels of miR-517-5p, miR-520a-5p, and miR-525-5p were observed in circulating plasma exosomes within 10 to 13 weeks of gestation in women affected with GH or PE when the comparison to the controls was performed using non-parametric statistical test (the Kruskal-Wallis test). GH: gestational hypertension; PE: preeclampsia. Outliers are marked by circles $\left({ }^{\circ}\right)$, and extremes by asterisks $\left({ }^{*}\right)$.

2.2. The High Accuracy of First Trimester C19MC MicroRNA Expression Profiling in Maternal Plasma Exosomes to Identify Women at a Risk of Later Development of GH or PE

The screening of individual C19MC microRNA biomarkers in plasma exosomes directed to the prediction of subsequent onset of GH reached a very high accuracy (miR-517-5p: AUC 0.812, $p<0.001$; miR-520a-5p: AUC 0.806, $p<0.001$; and miR-525-5p: AUC 0.802, $p<0.001$ ). The predictive performance of miR-517-5p, miR-520a-5p, and miR-525-5p reached $48.21 \%, 57.14 \%$, and $57.14 \%$ at $10.0 \%$ false positive rate (FPR) (Figure 2 ).

The combination of miR-520a-5p and miR-525-5p (AUC 0.808, $p<0.001$ ) had an advantage over using the miR-517-5p biomarker only (AUC 0.812, $p<0.001$ ), since it was able to predict a significantly higher number of women that later developed GH $(66.07 \%$ sensitivity at $10.0 \%$ FPR vs. $48.21 \%$ sensitivity at $10.0 \%$ FPR) (Figure 3). 
a

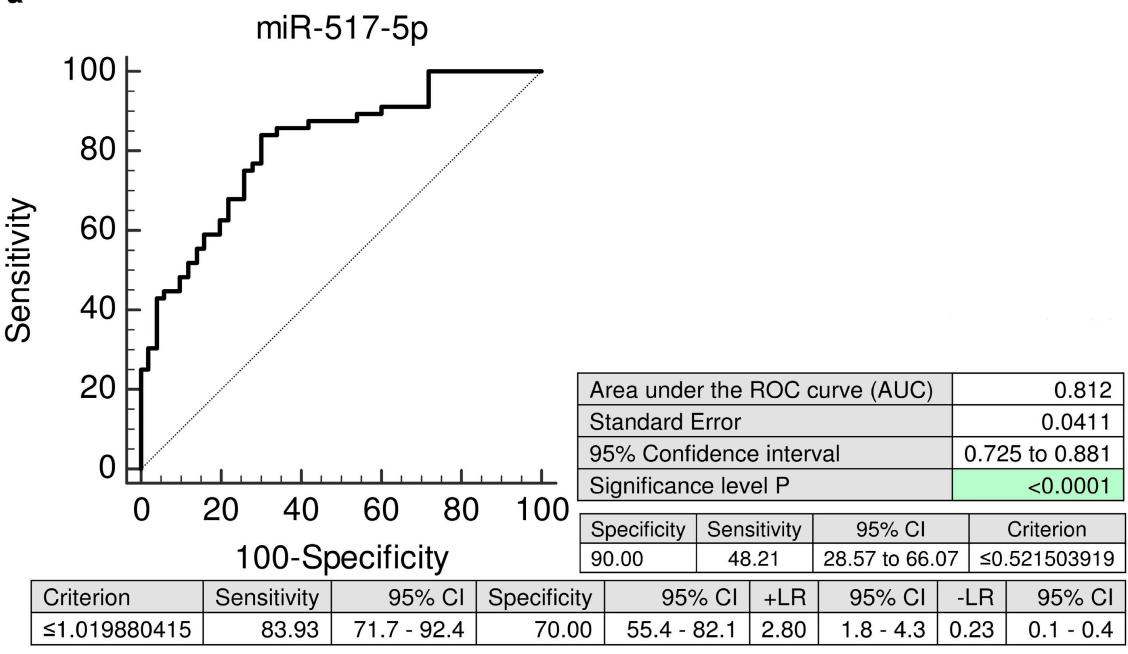

b

b $\quad$ miR-520a-5p

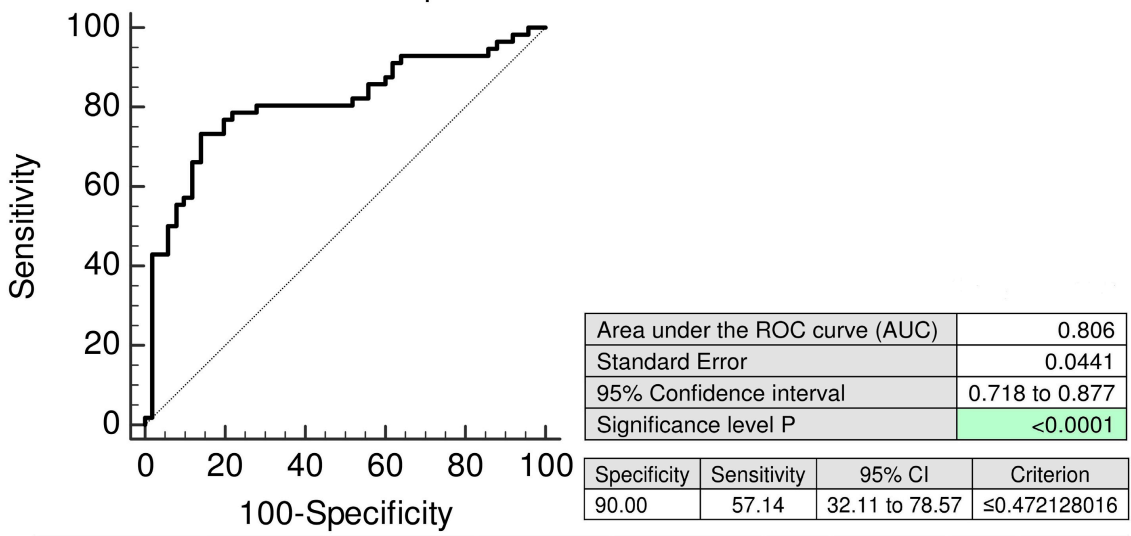

\begin{tabular}{|l|r|r|r|r|r|r|r|r|}
\hline Criterion & Sensitivity & $95 \% \mathrm{Cl}$ & Specificity & $95 \% \mathrm{Cl}$ & $+\mathrm{LR}$ & $95 \% \mathrm{Cl}$ & $-\mathrm{LR}$ & $95 \% \mathrm{Cl}$ \\
\hline
\end{tabular}

\begin{tabular}{|c|c|}
\hline & \\
\hline$\leq 0.664342907$ & 3.21 \\
\hline
\end{tabular}

C

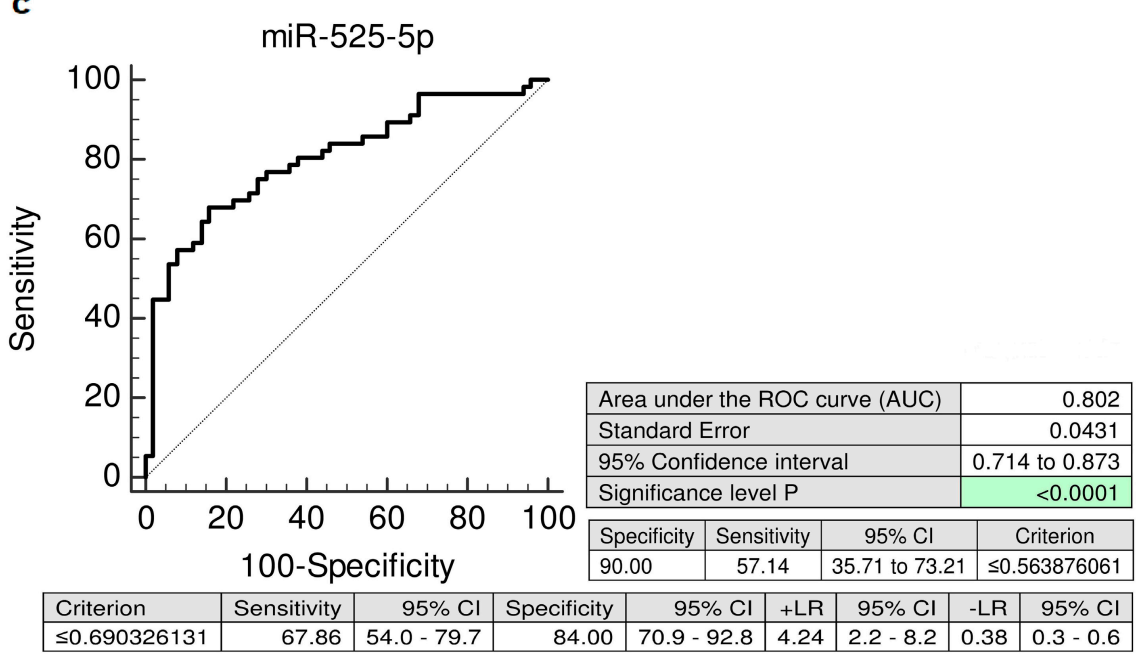

Figure 2. ROC curves-individual C19MC microRNA biomarkers-evaluation of the potential of the first trimester C19MC microRNA screening in plasma exosomes to predict later onset of GH. Decreased levels of miR-517-5p, miR-520a-5p, and miR-525-5p were detected in women destinated to develop GH when the comparison to the controls was performed both $(\mathbf{a}-\mathbf{c})$. GH: gestational hypertension. 
miR-520a-5p+miR-525-5p

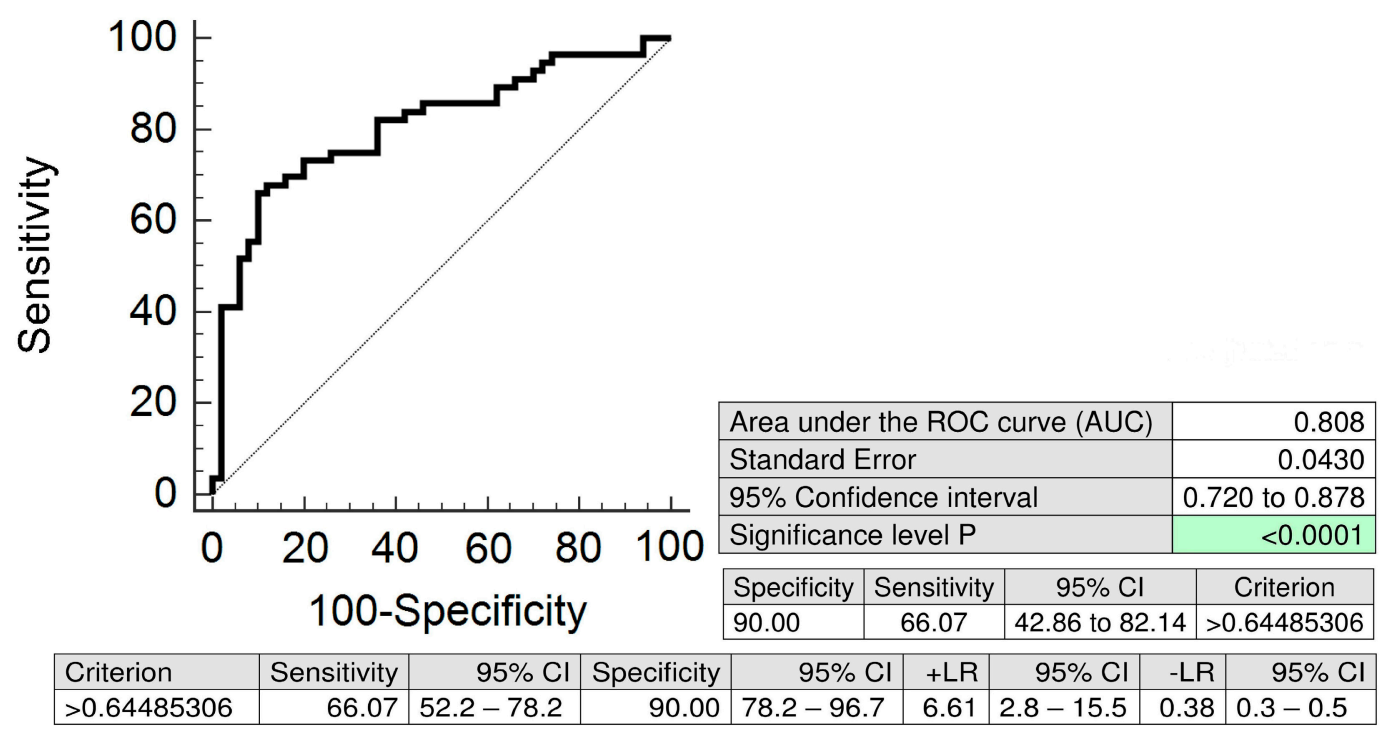

Figure 3. ROC curves-the best combination of C19MC microRNA biomarkers-evaluation of the potential of the first trimester C19MC microRNA screening in plasma exosomes to predict later onset of $\mathrm{GH}$. The combination of miR-520a-5p and miR-525-5p showed the best predictive performance for the prediction of the later occurrence of GH (66.07\% sensitivity at $10.0 \%$ FPR). GH: gestational hypertension.

Similarly, the ROC curve analyses, revealed significantly lower levels of miR-517-5p (AUC 0.634, $p=0.022,27.91 \%$ sensitivity at $10.0 \%$ FPR), miR-520a-5p (AUC $0.699, p<0.001,41.86 \%$ sensitivity at $10.0 \%$ FPR), and miR-525-5p (AUC 0.698, $p<0.001,39.53 \%$ sensitivity at $10.0 \%$ FPR) in a substantial proportion of mothers during the first trimester of gestation that subsequently developed PE (Figure 4).

a

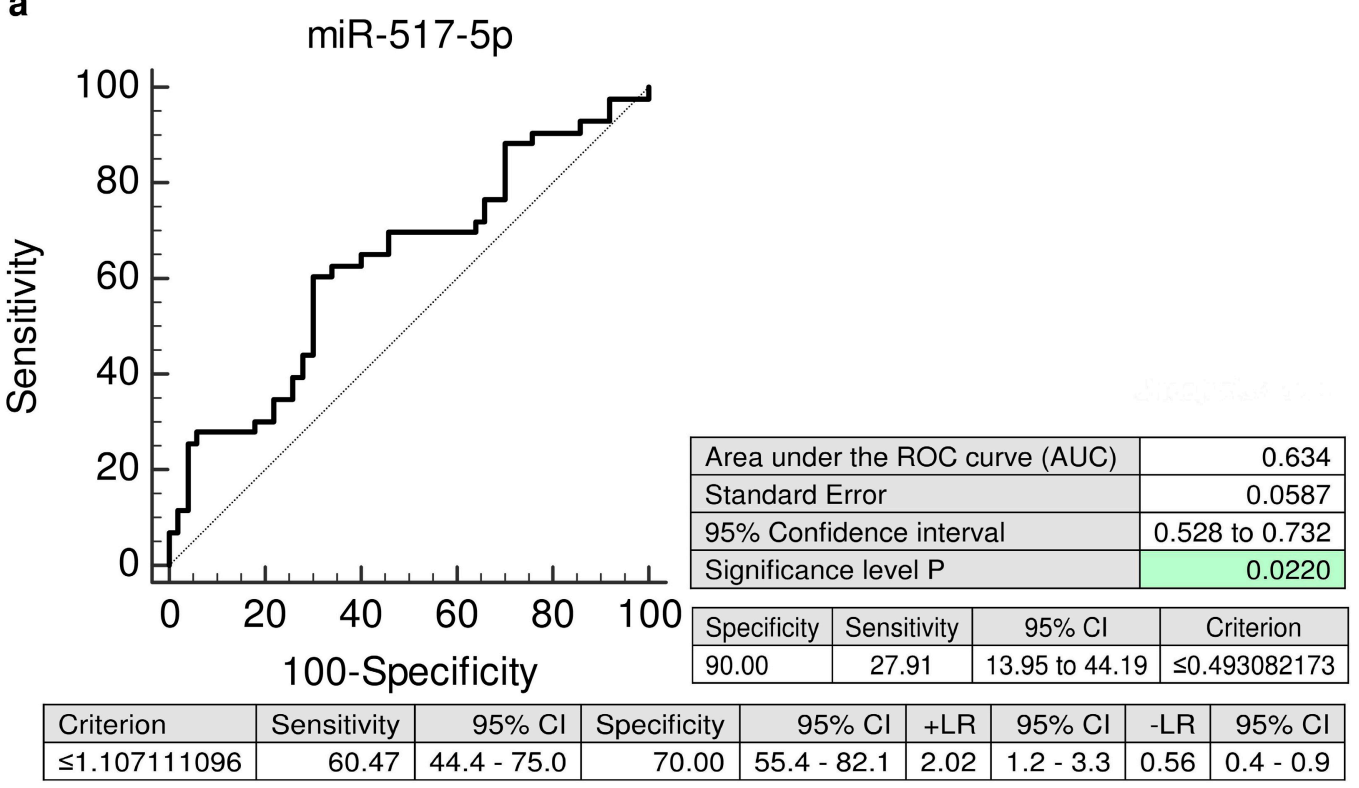

Figure 4. Cont. 


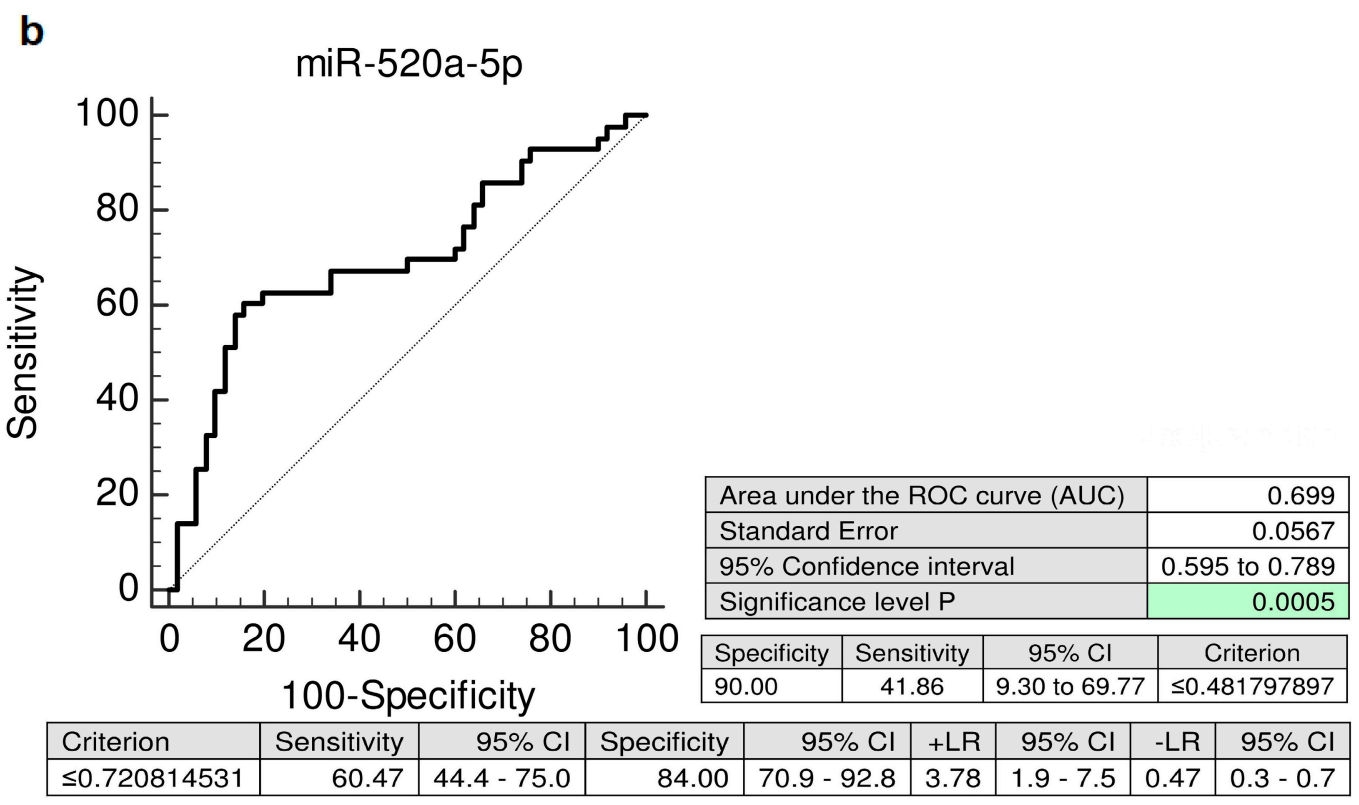

C

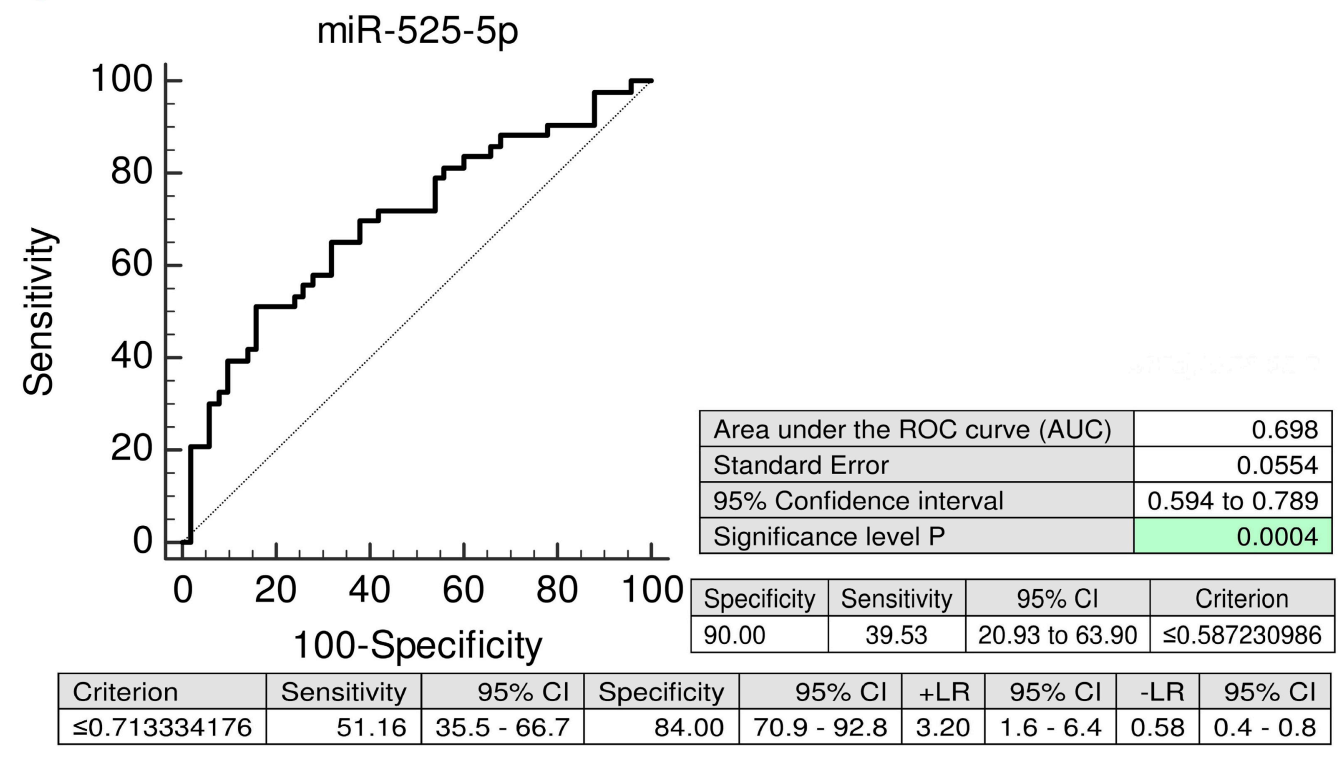

Figure 4. ROC curves-individual C19MC microRNA biomarkers-evaluation of the potential of the first trimester C19MC microRNA screening in plasma exosomes to predict subsequent onset of PE. Decreased levels of miR-517-5p, miR-520a-5p, and miR-525-5p were detected in women destinated to develop PE when the comparison to the controls was performed $(\mathbf{a}-\mathbf{c})$. PE: preeclampsia.

The combined screening of miR-517-5p, miR-520a-5p, and miR-525-5p was superior over using individual C19MC microRNA biomarkers or their dual combinations, since it was able to predict the highest number of women with the subsequent onset of PE (AUC 0.719, $p<0.001,44.19 \%$ sensitivity at 10.0\% FPR) (Figure 5). 


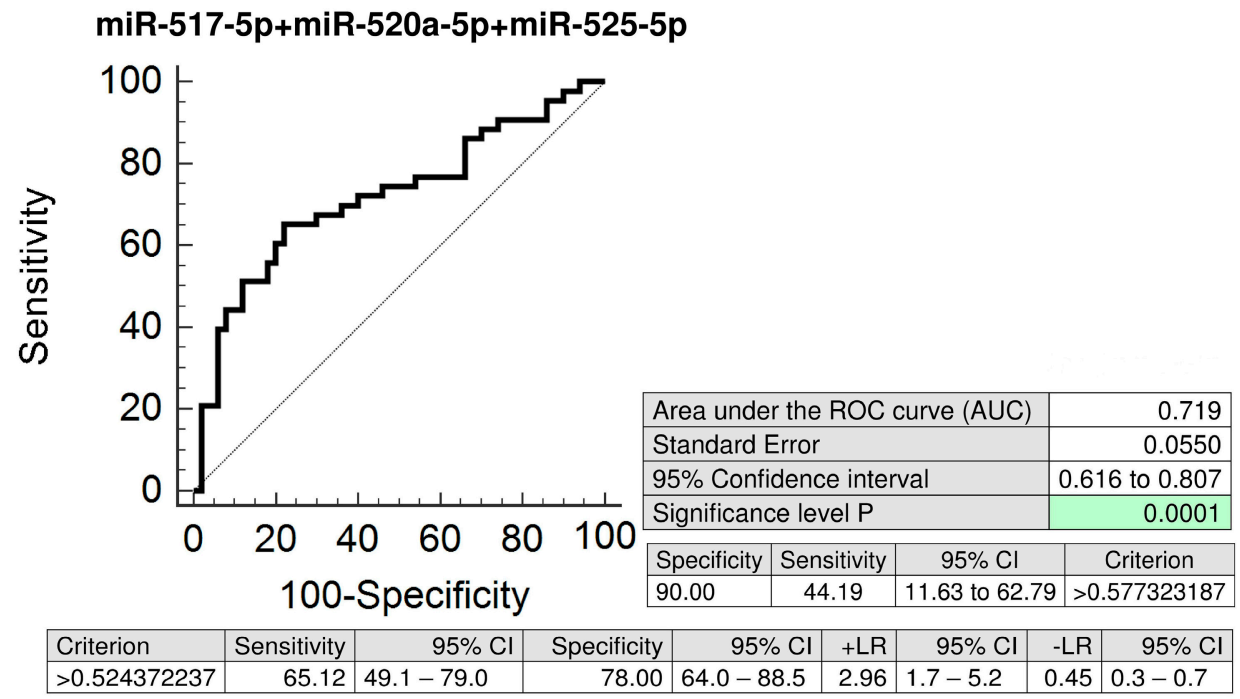

Figure 5. ROC curves-the best combination of C19MC microRNA biomarkers-evaluation of the potential of the first trimester C19MC microRNA screening in plasma exosomes to predict subsequent onset of PE. The combination of miR-517-5p, miR-520a-5p, and miR-525-5p showed the best predictive performance for the prediction of the later occurrence of PE (44.19\% sensitivity at $10.0 \%$ FPR). PE: preeclampsia.

2.3. MiR-520a-5p Represents a Novel Maternal Plasma Exosome C19MC MicroRNA Biomarker for Prediction of Later Onset of FGR

The Kruskal-Wallis test indicated the down-regulation of miR-520a-5p in circulating plasma exosomes during the first trimester of gestation in women carrying subsequently growth-restricted fetuses (Figure 6).

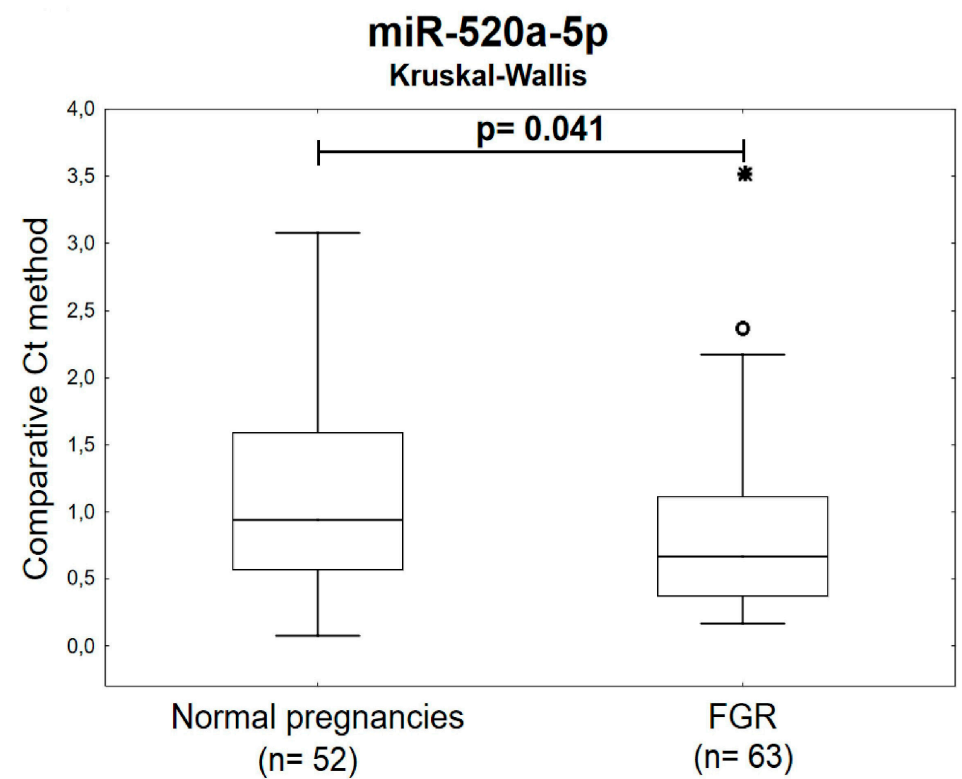

Figure 6. Down-regulation of miR-520a-5p in plasma exosomes during the first trimester of gestation in women with subsequent onset of FGR. Decreased levels of miR-520a-5p were observed in circulating plasma exosomes within 10 to 13 weeks of gestation in women affected with FGR when the comparison to the controls was performed using the Kruskal-Wallis test. FGR: fetal growth restriction. Outliers are marked by circles $\left({ }^{\circ}\right)$, and extremes by asterisks $\left({ }^{*}\right)$ 
The predictive performance of miR-520a-5p reaches $22.22 \%$ sensitivity at $10.0 \%$ FPR (AUC 0.611 , $p=0.037$ ) (Figure 7).

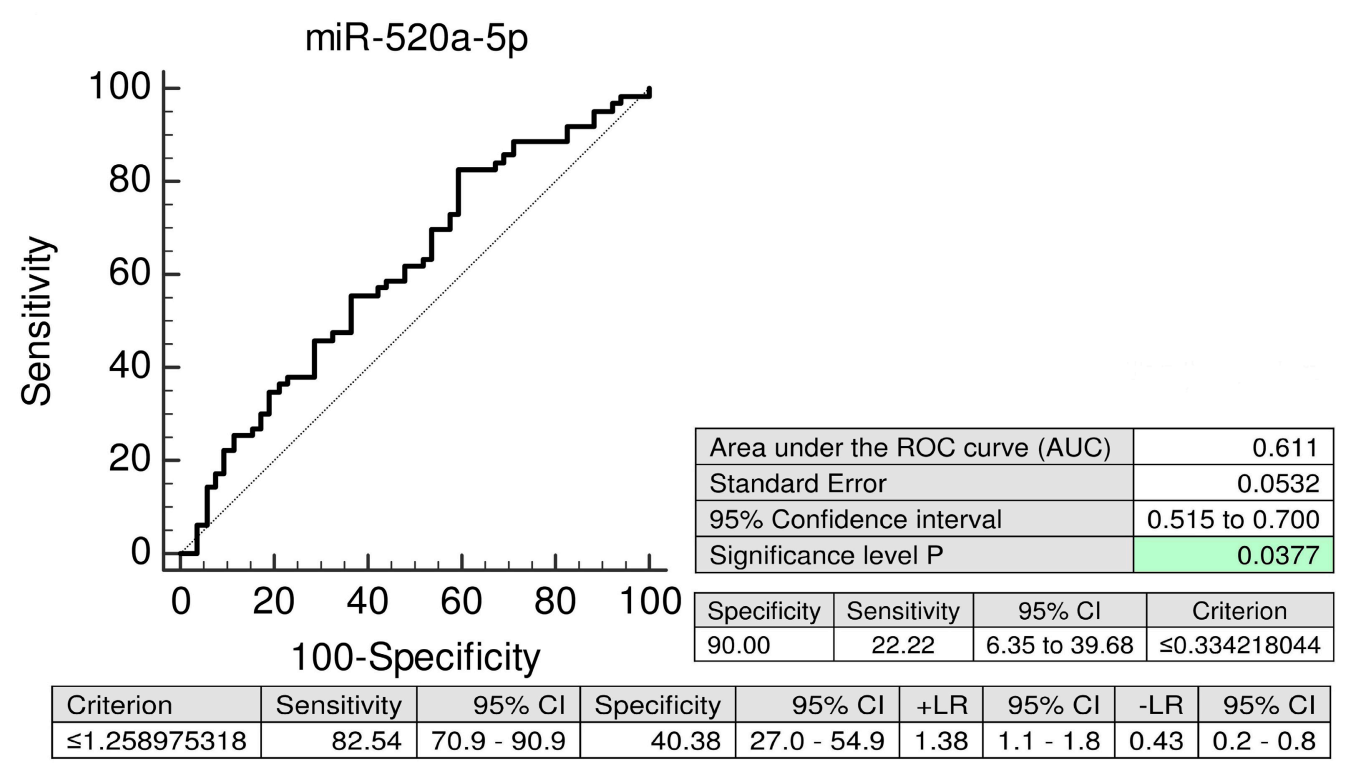

Figure 7. ROC curves-evaluation of the potential of the first trimester miR-520a-5p biomarker screening in plasma exosomes to predict subsequent onset of FGR. Decreased levels of miR-520a-5p were detected in women destinated to develop FGR when the comparison to the controls was performed. FGR: fetal growth restriction.

\section{Discussion}

To our knowledge, no data on C19MC microRNA profiling in maternal plasma exosomes during the first trimester of gestation was reported.

We found out that first trimester circulating plasma exosomes possess the identical C19MC microRNA expression profile as placental tissues derived from patients with GH, PE, and FGR after labor [32].

In placental tissues, down-regulation of 4/15 tested C19MC microRNAs (miR-517-5p, miR-519d, miR-520a-5p, and miR-525-5p) was previously observed in GH patients [32]. After the investigation of maternal plasma exosome C19MC microRNA expression profile during the first trimester of gestation with the selection of C19MC microRNAs with diagnostical potential only (miR-516b-5p, miR-517-5p, miR-518b, miR-520a-5p, miR-520h, and miR-525-5p) [29], we observed the down-regulation of miR-517-5p, miR-520a-5p, and miR-525-5p in patients with later occurrence of GH, which is in compliance with the findings in placental tissues derived from $\mathrm{GH}$ patients during the delivery [32].

Similarly, in PE patients, down-regulation of 11/15 tested C19MC microRNAs (miR-515-5p, miR-517-5p, miR-518b, miR-518f-5p, miR-519a, miR-519d, miR-520a-5p, miR-520h, miR-524-5p, miR-525-5p, and miR-526a) was previously demonstrated [32]. Parallel, after the testing of C19MC microRNAs with diagnostical potential only (miR-516b-5p, miR-517-5p, miR-518b, miR-520a-5p, miR-520h, and miR-525-5p) [29] in maternal plasma exosomes during the first trimester of gestation, we identified decreased levels of miR-517-5p, miR-520a-5p, and miR-525-5p in patients that subsequently developed $\mathrm{PE}$, which corresponds to a considerable extent to the expression profiles observed in PE affected placental tissues [32].

Nevertheless, these data are opposed to the results of our previous studies [6,9], indicating first trimester upregulation of circulating C19MC microRNAs in maternal plasma with predictive accuracy of subsequent development of gestational hypertension (miR-516-5p, miR-517-5p, miR-518b, miR-520a-5p, and miR-520h) or preeclampsia (miR-517-5p). Other investigators also observed increased levels of some C19MC microRNAs (miR-520) in sera from 12 to 14 weeks of gestation in women, who later 
developed severe preeclampsia [7]. We believe that dissimilar expression profiles of C19MC microRNAs between maternal plasma and maternal plasma exosomes can be influenced by compilations stemming from several factors. At the very least, an expression of particular C19MC microRNA in maternal plasma is represented by the total sum of expression of this particular C19MC microRNA in individual cells located in different areas of placenta, which currently undergo apoptosis, release placental debris into the maternal circulation, and actively secrete exosomes mediating intercellular communication [9].

However, the predictive accuracy of first trimester C19MC microRNA screening for the diagnosis of gestational hypertension is significantly higher in case of expression profiling of miR-517-5p (AUC $0.812, p<0.001$ vs. AUC 0.752, $p=0.002$ ) and miR-520a-5p: (AUC 0.806, $p<0.001$ vs. AUC 0.688 , $p=0.031$ in maternal plasma exosomes compared to expression profiling of whole maternal plasma samples [6].

In case of preeclampsia, the predictive accuracy of miR-517-5p is nearly identical for maternal plasma exosomes and whole maternal plasma samples (AUC 0.634, $p=0.022$ vs. AUC 0.700, $p=0.045$ ) [9]. But, maternal plasma exosome C19MC microRNA profiling significantly improved the predictive accuracy of miR-520a-5p (AUC 0.699, $p<0.001$ vs. AUC $0.495, p=0.951$ ) and miR-525-5p (AUC $0.698, p<0.001$ vs. AUC $0.475, p=0.755$ ) for preeclampsia [9]. In addition, the best predictive performance for preeclampsia was achieved when maternal plasma exosome combined profiling of miR-517-5p, miR-520a-5p, and miR-525-5p (AUC 0.719, $p<0.001$ ) was performed.

In case of FGR, placental tissues showed down-regulation of 6/15 tested C19MC microRNAs (miR-517-5p, miR-518f-5p, miR-519a, miR-519d, miR-520a-5p, and miR-525-5p) [32]. Maternal plasma exosomal profiling of selected C19MC microRNAs [29] revealed a novel down-regulated biomarker during the first trimester of gestation (miR-520a-5p) for women destinated to develop FGR, which was not identified when whole maternal plasma analysis was performed [9].

This study confirmed the former hypothesis, that the exosomes released to the systemic circulation represent unique non-invasive source of signalling molecules, including microRNAs, whose aberrant expression profile reflects expression profile of the parent cells (in this particular event the trophoblast cells) $[22,23]$. These observations support the idea that placenta-derived exosomes may be utilized as a part of first trimester screening to identify a significant proportion of women at a risk of later development of pregnancy-related complications such as gestational hypertension, preeclampsia, and FGR [22]. The only weakness of this approach is that the screening of C19MC microRNAs in plasma exosomes is not able to differentiate during the first trimester of gestation between the women that later develop GH and those ones that later develop PE, since the down-regulation of the same biomarkers (miR-517-5p, miR-520a-5p, and miR-525-5p) is present from early gestation. Nevertheless, through the mediation of this approach, novel microRNA biomarkers may be identified at some time in the future, which would be able to differentiate between women at a risk of GH and at risk of PE, to enable the primary prevention of preeclampsia via the early administration of low-dose aspirin [33-35].

Nevertheless, recent findings confirmed that even in women at a high risk of pregnancies with small-for-gestational-age foetuses the administration of aspirin at a dose of $\geq 100 \mathrm{mg}$ starting at or before 16 weeks of gestation is recommended [36-38]. Therefore, miR-520a-5p may be a novel promising placental specific biomarker for FGR with a potential of early stratification of high-risk pregnancies, which may benefit from primary prevention strategies as well.

\section{Materials and Methods}

\subsection{Patients Cohort}

The study had a retrospective design, it was performed in 6/2011-2/2019. The study cohort involved singleton pregnancies of Caucasian descent only. Of 4356 women undergoing first trimester screening at 10-13 weeks of gestation, 3092 women were finally followed-up and delivered in the Institute for the Care of Mother and Child, Prague, Czech Republic, 1189 women were followed-up 
and delivered in another health care provider, and in 75 women gestation was terminated for fetal anomaly or missed abortion appeared.

The case control study nested in a cohort involved women that later developed relevant pregnancy-related complications (57 GH, 43 PE, and 63 FGR) [39-42]. Finally, 13 of 43 PE patients developed mild PE, 30 of 43 PE patients suffered from severe PE, 10 of 43 PE patients were diagnosed with early PE (before 34 week of gestation) and 33 of 43 PE patients delivered after 34 week of gestation (late PE) [39-41]. Superimposed preeclampsia occurred in 5 out of 43 cases [39-41].

Of 63 pregnancies complicated with FGR, 4 foetuses were delivered before 32 week of gestation (early FGR), other 59 cases were diagnosed with late form of FGR (diagnosed after 32 week of gestation) [42].

Oligohydramnios or anhydramnios were found in 1 PE case and 16 FGR-affected foetuses.

Aberrant index of pulsatility (PI) was detected in arteria umbilicalis (above 95th percentile, $3 \mathrm{PE}$ cases, 23 FGR cases), arteria cerebri media (below 5th percentile, 3 PE cases, 14 FGR cases), arteria uterine (above 95th percentile, 7 PE case, 4 FGR cases), and Ductus venosus ( $>1,3$ FGR cases) $[43,44]$. The aberrant cerebro-placental ratio (CPR), below 5th percentile, was detected in 7 PE cases and 47 FGR cases [45-48]. Absent and/or zero diastolic flow in the arteria umbilicalis was present in 3 FGR cases [49,50]. An absence of flow during atrial contraction in Ductus venosus was detected in 1 FGR case $[51,52]$. The presence of unilateral or bilateral diastolic notch in the uterine artery was observed in 7 PE cases and 5 FGR cases [53,54].

The control group, normal pregnancies without complications delivering full term, healthy infants after 37 weeks of gestation weighting $>2500 \mathrm{~g}$, was selected on the basis of equal gestational age, equal age of women at the time of sampling and equal plasma sample storage times. The control group was separated into two subgroups and involved 102 cases altogether (the group 1 consisted of 50 cases, and the group 2 of 52 cases).

The clinical characteristics of the controls and complicated pregnancies are outlined in Table 1.

Written informed consent was provided for all participants included in the study. The study was approved by the Ethics Committee of the Third Faculty of Medicine, Prague, Czech Republic (Implication of placenta-specific microRNAs in maternal circulation for diagnosis and prediction of placental insufficiency, date of approval: 7.4.2011). 
Table 1. Clinical characteristics of the controls and complicated pregnancies.

\begin{tabular}{|c|c|c|c|c|c|c|}
\hline & $\begin{array}{l}\text { Control Group } 1 \\
(n=50)\end{array}$ & $\begin{array}{l}\text { Control Group } 2 \\
(n=52)\end{array}$ & $\begin{array}{l}\mathrm{PE} \\
(n=43)\end{array}$ & $\begin{array}{l}\text { FGR } \\
(n=63)\end{array}$ & $\begin{array}{l}\text { GH } \\
(n=57)\end{array}$ & $p$-Value \\
\hline \multicolumn{7}{|l|}{ At sampling } \\
\hline $\begin{array}{l}\text { Maternal age (years); mean } \\
\pm \text { SE }\end{array}$ & $31.88 \pm 0.56$ & $31.21 \pm 0.56$ & $32.34 \pm 0.73$ & $33.42 \pm 0.57$ & $32.15 \pm 0.63$ & - \\
\hline median (range) & $32(23-39)$ & $31(23-41)$ & $31(23-46)$ & $33(22-44)$ & $32(22-42)$ & - \\
\hline $\begin{array}{l}\text { Gestational age (weeks); } \\
\text { mean } \pm \text { SE }\end{array}$ & $10.69 \pm 0.14$ & $10.40 \pm 0.08$ & $10.82 \pm 0.18$ & $10.37 \pm 0.07$ & $10.84 \pm 0.13$ & - \\
\hline median (range) & $10.29(9.86-13.71)$ & $10.29(10.0-13.43)$ & $10.29(9.86-13.86)$ & $10.29(9.86-13.29)$ & $10.43(9.71-14.0)$ & - \\
\hline \multicolumn{7}{|l|}{ At delivery } \\
\hline $\begin{array}{l}\text { Gestational age (weeks); } \\
\text { mean } \pm \text { SE }\end{array}$ & $40.11 \pm 0.11$ & $39.75 \pm 0.15$ & $36.0 \pm 0.49$ & $36.68 \pm 0.30$ & $39.32 \pm 0.16$ & $\begin{array}{l}\text { PE vs. Control group1; } p<0.001 \\
\text { FGR vs. Control group2; } p<0.001\end{array}$ \\
\hline median (range) & $40.29(37.71-42.0)$ & $40.0(37.29-41.86)$ & $36.71(28.0-40.71)$ & $37.29(28.29-40.29)$ & $39.14(36.0-41.71)$ & $\begin{array}{l}\text { PE vs. Control group1; } p<0.001 \\
\text { FGR vs. Control group2; } p<0.001\end{array}$ \\
\hline \multicolumn{7}{|l|}{ Blood pressure (mmHg) } \\
\hline Systolic; mean \pm SE & $122.06 \pm 1.58$ & $122.05 \pm 1.74$ & $154.2 \pm 2.04$ & $124.91 \pm 2.27$ & $148.97 \pm 2.42$ & $\begin{array}{l}\text { PE vs. Control group1; } p<0.001 \\
\text { GH vs. Control group1; } p<0.001\end{array}$ \\
\hline median (range) & $120(100-142)$ & $120(90-148)$ & $150(133-186)$ & 125 (86-177) & $150(107-200)$ & $\begin{array}{l}\text { PE vs. Control group1; } p<0.001 \\
\text { GH vs. Control group1; } p<0.001\end{array}$ \\
\hline Diastolic; mean \pm SE & $76.28 \pm 0.94$ & $77.64 \pm 1.28$ & $99.74 \pm 1.38$ & $79.7 \pm 1.56$ & $92.75 \pm 1.43$ & $\begin{array}{l}\text { PE vs. Control group1; } p<0.001 \\
\text { GH vs. Control group1; } p<0.001\end{array}$ \\
\hline median (range) & $76(65-88)$ & $78(58-93)$ & $100(80-120)$ & $80(59-109)$ & $95(70-114)$ & $\begin{array}{l}\text { PE vs. Control group1; } p<0.001 \\
\text { GH vs. Control group1; } p<0.001\end{array}$ \\
\hline $\begin{array}{l}\text { Fetal birth weight (grams); } \\
\text { mean } \pm \text { SE }\end{array}$ & $3521.02 \pm 47.32$ & $3476.42 \pm 46.33$ & $2551.90 \pm 143.12$ & $2179.46 \pm 60.72$ & $3503.87 \pm 64.55$ & $\begin{array}{l}\text { PE vs. Control group1; } p<.001 \\
\text { FGR vs. Control group2; } p<0.001\end{array}$ \\
\hline median (range) & $3520(2780-4240)$ & $3440(2690-4290)$ & $2565(930-4460)$ & $2260(746-3230)$ & $3480(2510-4670)$ & $\begin{array}{l}\text { PE vs. Control group1; } p<0.001 \\
\text { FGR vs. Control group2; } p<0.001\end{array}$ \\
\hline \multicolumn{7}{|l|}{ Mode of delivery } \\
\hline Vaginal & $36(72.0 \%)$ & $43(82.69 \%)$ & $7(16.28 \%)$ & $16(25.4 \%)$ & $36(71.93 \%)$ & $\begin{array}{l}\text { PE vs. Control group1; } p<0.001 \\
\text { FGR vs. Control group2; } p<0.001\end{array}$ \\
\hline CS & $14(28.0 \%)$ & $9(17.31 \%)$ & $36(83.72 \%)$ & $47(74.6 \%)$ & $16(28.07 \%)$ & $\begin{array}{l}\text { PE vs. Control group1; } p<0.001 \\
\text { FGR vs. Control group2; } p<0.001\end{array}$ \\
\hline
\end{tabular}


Table 1. Cont.

\begin{tabular}{|c|c|c|c|c|c|c|}
\hline & $\begin{array}{l}\text { Control Group } 1 \\
(n=50)\end{array}$ & $\begin{array}{l}\text { Control Group } 2 \\
(n=52)\end{array}$ & $\begin{array}{l}\text { PE } \\
(n=43)\end{array}$ & $\begin{array}{l}\text { FGR } \\
(n=63)\end{array}$ & $\begin{array}{l}\text { GH } \\
(n=57)\end{array}$ & $p$-Value \\
\hline \multicolumn{7}{|c|}{ Fetal sex } \\
\hline Boy & $20(40.0 \%)$ & $27(51.92 \%)$ & $19(44.19 \%)$ & $32(56.14 \%)$ & $30(47.62 \%)$ & - \\
\hline Girl & $30(60.0 \%)$ & $25(48.08 \%)$ & $24(55.81 \%)$ & $25(43.86 \%)$ & $33(52.38 \%)$ & - \\
\hline \multicolumn{7}{|c|}{ Primiparity } \\
\hline Yes & $21(42.0 \%)$ & $31(59.62 \%)$ & $33(76.74 \%)$ & $35(61.4 \%)$ & $38(60.32 \%)$ & - \\
\hline No & $20(58.0 \%)$ & $21(40.38 \%)$ & $10(23.26 \%)$ & $22(38.6 \%)$ & $25(39.68 \%)$ & - \\
\hline
\end{tabular}

Continuous variables, compared using the ANOVA test or the Kruskal-Wallis test, are presented as mean \pm SE and median (range), respectively. Categorical variables, presented as number (percent), were compared using Chi-squared test. PE, preeclampsia; GH, gestational hypertension; FGR, fetal growth restriction; CS, Caesarean section; SE, standard error. 


\subsection{Processing of Samples}

Two millilitres of incoagulable peripheral blood (EDTA tubes) were centrifuged twice immediately after collection at $1200 \mathrm{rcf}(4600 \mathrm{rpm})$ for $10 \mathrm{~min}$ at room temperature. Plasma samples were then stored frozen at $-80^{\circ} \mathrm{C}$ until further processing.

\subsection{Isolation and Purification of Exosomes from Maternal Plasma Samples}

Exosomes were isolated from $0.6 \mathrm{~mL}$ of maternal plasma samples using miRCURYTM Exosome Isolation Kit-Serum and plasma (Exiqon, Woburn, MA, USA, no: 300101) according to the manufacturer's instructions. After the exosome isolation and purification, RNA was isolated immediately from $200 \mu \mathrm{L}$ supernatant using miRCURY ${ }^{\mathrm{TM}}$ RNA Isolation Kit-Biofluids (Exiqon, Woburn, MA, USA, no: 300112) according to manufacturer's instructions. After 3 min incubation of $200 \mu \mathrm{L}$ supernatant with $60 \mu \mathrm{L}$ Lysis Solution buffer, $1 \mu \mathrm{L}$ RNA spike-in (1 nM cell-miR-39, synthetic C. elegans microRNA, Qiagen, Hilden, Germany, no: MSY0000010) and $20 \mu \mathrm{L}$ Protein Precipitation Solution buffer were added into the mixture. In order to maximize yield of exosomal RNA, total elution volume of $100 \mu \mathrm{L}$ was used ( $50 \mu \mathrm{L}$ in 2 steps eluting with half of the recommended total volume each). DNA contamination of RNA was removed by the 30 min treatment of eluted RNA with $5 \mu \mathrm{L}$ DNase I (Thermo Fisher Scientific, Waltham, MA, USA, no: EN0521) at $37^{\circ} \mathrm{C}$.

The quality of the isolated exosomes was not checked using flow cytometry, electron microscopy, or other techniques, since we were not interested in exosomal subpopulations present in analysed samples or in performance of exosomal functional studies. The protocols of miRCURY'TM Exosome Isolation Kit-Serum and plasma (Exiqon, Woburn, MA, USA, no: 300101) are validated to allow subsequent microRNA isolation using the miRCURY'TM RNA Isolation Kit - Biofluids (Exiqon, Woburn, MA, USA, no: 300112) and improve the quality of the obtained microRNA signature.

\subsection{Reverse Transcription Reaction}

The analyzed C19MC microRNAs and cell-miR-39 were reverse transcribed into complementary DNA using TaqMan ${ }^{\text {TM }}$ MicroRNA Assays (Thermo Fisher Scientific, Waltham, MA, USA, miR-516b-5p no: 001281, miR-517-5p no: 001113, miR-518b no: 001156, miR-520a-5p no: 001168, miR-520h no: 001170, miR-525-5p no: 001174, and cell-miR-39 no: 000200), and TaqMan MicroRNA Reverse Transcription Kit (Thermo Fisher Scientific, Waltham, MA, USA, no: 4366597). Reverse transcription reaction was performed in a total reaction volume of $32 \mu \mathrm{L}$ in case of C19MC microRNAs and in a total reaction volume of $10 \mu \mathrm{L}$ in case of cell-miR-39 on a 7500 Real-Time PCR system (Thermo Fisher Scientific, Waltham, MA, USA) under predefined thermal cycling parameters: $30 \mathrm{~min}$ at $16^{\circ} \mathrm{C}, 30 \mathrm{~min}$ at $42^{\circ} \mathrm{C}$, 5 min at $85^{\circ} \mathrm{C}$, and then held at $4{ }^{\circ} \mathrm{C}[3,5,6,9,32]$.

\subsection{Quantification of Plasma Exosomal C19MC microRNAs by Real-Time PCR}

$15 \mu \mathrm{L}$ of cDNA corresponding to C19MC microRNAs and $4.4 \mu \mathrm{L}$ of cDNA corresponding to cell-miR-39 were mixed with components of TaqMan MicroRNA Assays (Thermo Fisher Scientific, Waltham, MA, USA, miR-516b-5p no: 001281, miR-517-5p no: 001113, miR-518b no: 001156, miR-520a-5p no: 001168, miR-520h no: 001170, miR-525-5p no: 001174, and cell-miR-39 no: 000200), and the ingredients of the TaqMan Universal PCR Master Mix (Thermo Fisher Scientific, Waltham, MA, USA, no: 4318157). The analysis was performed using a 7500 Real-Time PCR System under the conditions described in the TaqMan guidelines in a total reaction volume of $35 \mu \mathrm{L}$. All PCRs were performed in duplicates. A sample displaying the amplification signal before the 40th threshold cycle (Ct) was considered positive.

The expression of particular C19MC microRNA in maternal plasma exosomes was determined using the comparative $\mathrm{Ct}$ method [55] relative to the expression in the reference sample. RNA isolated from the pool of randomly selected maternal plasma samples derived from women at the first trimester with normal course of gestation was used as a reference sample for relative quantification. 
Two reference samples were used throughout the study (reference 1: the pool of 5 maternal plasma samples, reference 2: the pool of 8 maternal plasma samples).

Real-time PCR data were normalized to synthetic C. elegans microRNA (cell-miR-39, Qiagen, Hilden, Germany, no: MSY0000010) showing no sequence homology to any human microRNA: $2^{-\Delta \Delta \mathrm{Ct}}=[(\mathrm{Ct}$ particular C19MC microRNA-Ct cel-miR-39) tested sample-(Ct particular C19MC microRNA—Ct cel-miR-39) reference sample] [6,9].

\subsection{Statistical Analysis}

Normality of the data was assessed using Shapiro-Wilk test, which indicated that our experimental data did not follow a normal distribution (Table S1). Therefore, C19MC microRNA levels were primarily compared between groups using non-parametric test (the Kruskal-Wallis one-way analysis of variance with post-hoc test for the comparison among multiple groups). The significance level was established at a $p$-value of $p<0.05$.

Receivers operating characteristic (ROC) curves were constructed to calculate the area under the curve (AUC) and the best cut-off point for particular C19MC microRNA was used in order to calculate the respective sensitivity at $90.0 \%$ specificity, respectively (MedCalc Software bvba, Ostend, Belgium). For every possible threshold or cut-off value, the MedCalc program reports the sensitivity, specificity, likelihood ratio positive (LR+), and likelihood ratio negative (LR-).

To select the optimal combinations of C19MC microRNA biomarkers logistic regression was applied (MedCalc Software bvba, Ostend, Belgium). To perform a full ROC curve analysis the predicted probabilities were first saved and next used as a new variable in ROC curve analysis. The dependent variable used in logistic regression acted as the classification variable in the ROC curve analysis dialog box.

Box plots encompassing the median (the Kruskal-Wallis test) of gene expression values for particular C19MC microRNAs were generated using Statistica software (version 9.0; StatSoft, Inc., Tulsa, OK, USA). The upper and lower limits of the boxes represent the 75th and 25th percentiles (the Kruskal-Wallis test), respectively. The upper and lower whiskers indicate the maximum and minimum values that are no more than 1.5 times the span of the interquartile range (range of the values between the 25th and the 75th percentiles) (the Kruskal-Wallis test). Outliers are marked by circles, and extremes by asterisks.

The presentation of no statistically significant results is provided in Supplementary material (Table S2).

\section{Conclusions}

The down-regulation of miR-517-5p, miR-520a-5p, and miR-525-5p was observed in patients with later occurrence of GH and PE. Maternal plasma exosomal profiling of selected C19MC microRNAs also revealed a novel down-regulated biomarker during the first trimester of gestation (miR-520a-5p) for women destinated to develop FGR. First trimester circulating plasma exosomes possess the identical C19MC microRNA expression profile as placental tissues derived from patients with GH, PE and FGR during labour. The predictive accuracy of first trimester C19MC microRNA screening (miR-517-5p, miR-520a-5p, and miR-525-5p) for the diagnosis of GH and PE was significantly higher in case of expression profiling of maternal plasma exosomes compared to expression profiling of whole maternal plasma samples. Consecutive large-scale studies are needed to verify the findings resulting from this pilot study. Nevertheless, the performance of that kind of studies will be highly demanding, since ten thousand of the first trimester plasma samples have to be collected to get sufficient amount of cases who will subsequently develop pregnancy-related complications such as GH, PE, or FGR. For the purpose of this study we collected plasma samples from 4356 women to acquire 163 samples from women that later developed relevant pregnancy-related complications ( $57 \mathrm{GH}, 43 \mathrm{PE}$, and $63 \mathrm{FGR}$ ). 
Supplementary Materials: Supplementary materials can be found at http://www.mdpi.com/1422-0067/20/12/ 2972/s1.

Author Contributions: Conceptualization, I.H. and L.K.; methodology, I.H., K.K., and L.D.; software, I.H., K.K., L.D.; validation, I.H., K.K., and L.D.; formal analysis, I.H., K.K.; investigation, K.K. and L.D.; resources, I.H. and L.K.; data curation, I.H., K.K. and L.D.; writing—original draft preparation, I.H.; writing-review and editing, I.H. and K.K.; visualization, K.K.; supervision, I.H. and L.K.; project administration, I.H. and L.K.; funding acquisition, I.H. and L.K.

Funding: This research was funded by the Charles University, Prague, Czech Republic, grant numbers SVV no. 260386 and PROGRES Q34. All rights reserved.

Acknowledgments: All procedures were in accordance with the ethical standards of the responsible committee on human experimentation (institutional and national) and with the Helsinki Declaration of 1975, as revised in 2000.

Conflicts of Interest: The authors declare no conflict of interest.

$\begin{array}{ll}\text { Abbreviations } \\ \text { PE } & \text { Preeclampsia } \\ \text { FGR } & \text { Fetal growth restriction } \\ \text { GH } & \text { Gestational hypertension } \\ \text { C19MC } & \text { microRNA cluster on chromosome 19 } \\ \text { FGR } & \text { Fetal growth restriction } \\ \text { FPR } & \text { False positive rate } \\ \text { LR } & \text { Likelihood ratio } \\ \text { SE } & \text { Standard error } \\ \text { SD } & \text { Standard deviation } \\ \text { CPR } & \text { Cerebro-placental ratio } \\ \text { PI } & \text { Pulsatility index } \\ \text { EDTA } & \text { Ethylenediaminetetraacetic acid }\end{array}$

\section{References}

1. Gunel, T.; Zeybek, Y.G.; Akçakaya, P.; Kalelioğlu, I.; Benian, A.; Ermis, H.; Aydınlı, K. Serum microRNA expression in pregnancies with preeclampsia. Genet. Mol. Res. 2011, 10, 4034-4040. [CrossRef] [PubMed]

2. Yang, Q.; Lu, J.; Wang, S.; Li, H.; Ge, Q.; Lu, Z. Application of next-generation sequencing technology to profile the circulating microRNAs in the serum of preeclampsia versus normal pregnant women. Clin. Chim. Acta 2011, 412, 2167-2173. [CrossRef] [PubMed]

3. Hromadnikova, I.; Kotlabova, K.; Doucha, J.; Dlouha, K.; Krofta, L. Absolute and relative quantification of placenta-specific micrornas in maternal circulation with placental insufficiency-related complications. J. Mol. Diagn. 2012, 14, 160-167. [CrossRef] [PubMed]

4. Wu, L.; Zhou, H.; Lin, H.; Qi, J.; Zhu, C.; Gao, Z.; Wang, H. Circulating microRNAs are elevated in plasma from severe preeclamptic pregnancies. Reproduction 2012, 143, 389-397. [CrossRef] [PubMed]

5. Hromadnikova, I.; Kotlabova, K.; Ondrackova, M.; Kestlerova, A.; Novotna, V.; Hympanova, L.; Doucha, J.; Krofta, L. Circulating C19MC microRNAs in preeclampsia, gestational hypertension, and fetal growth restriction. Mediat. Inflamm. 2013, 2013, 186041. [CrossRef] [PubMed]

6. Hromadnikova, I.; Kotlabova, K.; Hympanova, L.; Doucha, J.; Krofta, L. First trimester screening of circulating C19MC microRNAs can predict subsequent onset of gestational hypertension. PLoS ONE 2014, 9, e113735. [CrossRef] [PubMed]

7. Ura, B.; Feriotto, G.; Monasta, L.; Bilel, S.; Zweyer, M.; Celeghini, C. Potential role of circulating microRNAs as early markers of preeclampsia. Taiwan J. Obstet. Gynecol. 2014, 53, 232-234. [CrossRef] [PubMed]

8. Miura, K.; Higashijima, A.; Murakami, Y.; Tsukamoto, O.; Hasegawa, Y.; Abe, S.; Fuchi, N.; Miura, S.; Kaneuchi, M.; Masuzaki, H. Circulating chromosome 19 miRNA cluster microRNAs in pregnant women with severe pre-eclampsia. J. Obstet. Gynaecol. Res. 2015, 41, 1526-1532. [CrossRef] [PubMed]

9. Hromadnikova, I.; Kotlabova, K.; Ivankova, K.; Krofta, L. First trimester screening of circulating C19MC microRNAs and the evaluation of their potential to predict the onset of preeclampsia and IUGR. PLoS ONE 2017, 12, e0171756. [CrossRef] 
10. Wommack, J.C.; Trzeciakowski, J.P.; Miranda, R.C.; Stowe, R.P.; Ruiz, R.J. Micro RNA clusters in maternal plasma are associated with preterm birth and infant outcomes. PLoS ONE 2018, 13, e0199029. [CrossRef]

11. Pillay, P.; Moodley, K.; Moodley, J.; Mackraj, I. Placenta-derived exosomes: Potential biomarkers of preeclampsia. Int. J. Nanomed. 2017, 12, 8009-8023. [CrossRef] [PubMed]

12. Yu, B.; Zhang, X.; Li, X. Exosomes derived from mesenchymal stem cells. Int. J. Mol. Sci. 2014, 15, 4142-4157. [CrossRef] [PubMed]

13. Tomasetti, M.; Lee, W.; Santarelli, L.; Neuzil, J. Exosome-derived microRNAs in cancer metabolism: Possible implications in cancer diagnostics and therapy. Exp. Mol. Med. 2017, 49, e285. [CrossRef] [PubMed]

14. Zhou, S.; Abdouh, M.; Arena, V.; Arena, M.; Arena, G.O. Reprogramming malignant cancer cells toward a benign phenotype following exposure to human embryonic stem cell microenvironment. PLoS ONE 2017, 12, e0169899. [CrossRef] [PubMed]

15. Théry, C.; Zitvogel, L.; Amigorena, S. Exosomes: Composition, biogenesis and function. Nat. Rev. Immunol. 2002, 2, 569-579. [CrossRef] [PubMed]

16. Kalra, H.; Adda, C.G.; Liem, M.; Ang, C.S.; Mechler, A.; Simpson, R.J.; Hulett, M.D.; Mathivanan, S. Comparative proteomics evaluation of plasma exosome isolation techniques and assessment of the stability of exosomes in normal human blood plasma. Proteomics 2013, 13, 3354-3364. [CrossRef]

17. Harding, C.V.; Heuser, J.E.; Stahl, P.D. Exosomes: Looking back three decades and into the future. J. Cell Biol. 2013, 200, 367-371. [CrossRef]

18. Mitchell, M.D.; Peiris, H.N.; Kobayashi, M.; Koh, Y.Q.; Duncombe, G.; Illanes, S.E.; Rice, G.E.; Salomon, C. Placental exosomes in normal and complicated pregnancy. Am. J. Obstet. Gynecol. 2015, 213, S173-S181. [CrossRef]

19. Kalluri, R. The biology and function of exosomes in cancer. J. Clin. Investig. 2016, 126, 1208-1215. [CrossRef]

20. Kalluri, R.; LeBleu, V.S. Discovery of double-stranded genomic DNA in circulating exosomes. Cold Spring Harb. Symp. Quant. Biol. 2016, 81, 275-280. [CrossRef]

21. Tkach, M.; Théry, C. Communication by extracellular vesicles: Where we are and where we need to go. Cell 2016, 164, 1226-1232. [CrossRef] [PubMed]

22. Salomon, C.; Guanzon, D.; Scholz-Romero, K.; Longo, S.; Correa, P.; Illanes, S.E.; Rice, G.E. Placental Exosomes as Early Biomarker of Preeclampsia: Potential Role of Exosomal MicroRNAs Across Gestation. J. Clin. Endocrinol. Metab. 2017, 102, 3182-3194. [CrossRef]

23. Batista, I.A.; Melo, S.A. Exosomes and the Future of Immunotherapy in Pancreatic Cancer. Int. J. Mol. Sci. 2019, 20, 567. [CrossRef] [PubMed]

24. Noguer-Dance, M.; Abu-Amero, S.; Al-Khtib, M.; Lefèvre, A.; Coullin, P.; Moore, G.E.; Cavaillé, J. The primate-specific microRNA gene cluster (C19MC) is imprinted in the placenta. Hum. Mol. Genet. 2010, 19, 3566-3582. [CrossRef] [PubMed]

25. Augello, C.; Vaira, V.; Caruso, L.; Destro, A.; Maggioni, M.; Park, Y.N.; Montorsi, M.; Santambrogio, R.; Roncalli, M.; Bosari, S. MicroRNA profiling of hepatocarcinogenesis identifies C19MC cluster as a novel prognostic biomarker in hepatocellular carcinoma. Liver Int. 2012, 32, 772-782. [CrossRef] [PubMed]

26. Flor, I.; Bullerdiek, J. The dark side of a success story: microRNAs of the C19MC cluster in human tumours. J. Pathol. 2012, 227, 270-274. [CrossRef]

27. Vaira, V.; Elli, F.; Forno, I.; Guarnieri, V.; Verdelli, C.; Ferrero, S.; Scillitani, A.; Vicentini, L.; Cetani, F.; Mantovani, G.; et al. The microRNA cluster C19MC is deregulated in parathyroid tumours. J. Mol. Endocrinol. 2012, 49, 115-124. [CrossRef]

28. Rippe, V.; Dittberner, L.; Lorenz, V.N.; Drieschner, N.; Nimzyk, R.; Sendt, W.; Junker, K.; Belge, G.; Bullerdiek, J. The two stem cell microRNA gene clusters C19MC and miR-371-3 are activated by specific chromosomal rearrangements in a subgroup of thyroid adenomas. PLoS ONE 2015, 5, e9485. [CrossRef]

29. Kotlabova, K.; Doucha, J.; Hromadnikova, I. Placental-specific microRNA in maternal circulationIdentification of appropriate pregnancy-associated microRNAs with diagnostic potential. J. Reprod. Immunol. 2011, 89, 185-191. [CrossRef]

30. Hromadnikova, I. Extracellular nucleic acids in maternal circulation as potential biomarkers for placental insufficiency. DNA Cell Biol. 2012, 31, 1221-1232. [CrossRef]

31. Devor, E.; Santillan, D.; Scroggins, S.; Warrier, A.; Santillan, M. Trimester-specific plasma exosome microRNA expression profiles in preeclampsia. J. Matern. Fetal Neonatal Med. 2019, 30, 1-9. [CrossRef] [PubMed] 
32. Hromadnikova, I.; Kotlabova, K.; Ondrackova, M.; Pirkova, P.; Kestlerova, A.; Novotna, V.; Hympanova, L.; Krofta, L. Expression profile of C19MC microRNAs in placental tissue in pregnancy-related complications. DNA Cell Biol. 2015, 34, 437-457. [CrossRef] [PubMed]

33. Roberge, S.; Bujold, E.; Nicolaides, K.H. Aspirin for the prevention of preterm and term preeclampsia: Systematic review and metaanalysis. Am. J. Obstet. Gynecol. 2018, 218, 287-293. [CrossRef] [PubMed]

34. Zhu, J.; Huang, R.; Zhang, J.; Ye, W.; Zhang, J. A prophylactic low-dose aspirin earlier than 12 weeks until delivery should be considered to prevent preeclampsia. Med. Hypotheses 2018, 121, 127-130. [CrossRef] [PubMed]

35. Wright, D.; Rolnik, D.L.; Syngelaki, A.; de Paco Matallana, C.; Machuca, M.; de Alvarado, M.; Mastrodima, S.; Tan, M.Y.; Shearing, S.; Persico, N.; et al. Aspirin for Evidence-Based Preeclampsia Prevention trial: Effect of aspirin on length of stay in the neonatal intensive care unit. Am. J. Obstet. 2018, 218, 612.e1-612.e6. [CrossRef] [PubMed]

36. Vayssière, C.; Sentilhes, L.; Ego, A.; Bernard, C.; Cambourieu, D.; Flamant, C.; Gascoin, G.; Gaudineau, A.; Grangé, G.; Houfflin-Debarge, V.; et al. Fetal growth restriction and intra-uterine growth restriction: Guidelines for clinical practice from the French College of Gynaecologists and Obstetricians. Eur. J. Obstet. Gynecol. Reprod. Biol. 2015, 193, 10-18. [CrossRef] [PubMed]

37. Nawathe, A.; David, A.L. Prophylaxis and treatment of foetal growth restriction. Best Pract. Res. Clin. Obstet. Gynaecol. 2018, 49, 66-78. [CrossRef]

38. Groom, K.M.; David, A.L. The role of aspirin, heparin, and other interventions in the prevention and treatment of fetal growth restriction. Am. J. Obstet. Gynecol. 2018, 218, S829-S840. [CrossRef]

39. Report of the National High Blood Pressure Education Program Working Group on High Blood Pressure in Pregnancy. Am. J. Obstet. Gynecol. 2000, 183, S1-S22. [CrossRef]

40. Diagnosis and management of preeclampsia and eclampsia. ACOG Practice Bulletin No. 33. American College of Obstetricians and Gynecologists. Obstet. Gynecol. 2002, 99, 159-167.

41. American College of Obstetricians and Gynecologists; Task Force on Hypertension in Pregnancy. Hypertension in pregnancy. Report of the American College of Obstetricians and Gynecologists' Task Force on Hypertension in Pregnancy. Obstet. Gynecol. 2013, 122, 1122-1131.

42. American College of Obstetricians and Gynecologists. ACOG Practice bulletin no. 134: Fetal growth restriction. Obstet. Gynecol. 2013, 121, 1122-1133. [CrossRef] [PubMed]

43. Cnossen, J.S.; Morris, R.K.; ter Riet, G.; Mol, B.W.; van der Post, J.A.; Coomarasamy, A.; Zwinderman, A.H.; Robson, S.C.; Bindels, P.J.; Kleijnen, J.; et al. Use of uterine artery Doppler ultrasonography to predict pre-eclampsia and intrauterine growth restriction: A systematic review and bivariable meta-analysis. Cmaj 2008, 178, 701-711. [CrossRef] [PubMed]

44. Society for Maternal-Fetal Medicine Publications Committee; Berkley, E.; Chauhan, S.P.; Abuhamad, A. Doppler assessment of the fetus with intrauterine growth restriction. Am. J. Obstet. Gynecol. 2012, 206, 300-308, Erratum in Am. J. Obstet. Gynecol. 2015, 212, 246. Am. J. Obstet. Gynecol. 2012, 206, 508. [CrossRef] [PubMed]

45. Gramellini, D.; Folli, M.C.; Raboni, S.; Vadora, E.; Merialdi, A. Cerebral-umbilical Doppler ratio as a predictor of adverse perinatal outcome. Obstet. Gynecol. 1992, 74, 416-420. [CrossRef]

46. Arias, F. Accuracy of the middle-cerebral-to-umbilical-artery resistance index ratios in the prediction of neonatal outcome in patients at high risk for fetal and neonatal complications. Am. J. Obstet. Gynecol. 1994, 171, 1541-1545. [CrossRef]

47. Arbeille, P.; Maulik, D.; Fignon, A.; Stale, H.; Berson, M.; Bodard, S.; Locatelli, A. Assessment of the fetal $\mathrm{pO}_{2}$ changes by cerebral and umbilical Doppler on lamb fetuses during acute hypoxia. Ultrasound Med. Biol. 1995, 21, 861-870. [CrossRef]

48. Bahado-Singh, R.O.; Kovanci, E.; Jeffres, A.; Oz, U.; Deren, O.; Copel, J.; Mari, G. The Doppler cerebroplacental ratio and perinatal outcome in intrauterine growth restriction. Am. J. Obstet. Gynecol. 1999, 180, 750-756. [CrossRef]

49. Fleischer, A.; Schulman, H.; Farmakides, G.; Bracero, L.; Blattner, P.; Randolph, G. Umbilical artery velocity waveforms and intrauterine growth retardation. Am. J. Obstet. Gynecol. 1985, 151, 502-506. [CrossRef]

50. Soregaroli, M.; Bonera, R.; Danti, L.; Dinolfo, D.; Taddei, F.; Valcamonico, A.; Frusca, T. Prognostic role of umbilical artery Doppler velocimetry in growth-restricted fetuses. J. Matern. Fetal Neonatal Med. 2002, 11, 199-203. [CrossRef] 
51. Baschat, A.A.; Gembruch, U.; Weiner, C.P.; Harman, C.R. Qualitative venous Doppler waveform analysis improves prediction of critical perinatal outcomes in premature growth-restricted fetuses. Ultrasound Obstet. Gynecol. 2003, 22, 240-245. [CrossRef] [PubMed]

52. Seravalli, V.; Baschat, A.A. A uniform management approach to optimize outcome in fetal growth restriction. Obstet. Gynecol. Clin. N. Am. 2015, 42, 275-288. [CrossRef] [PubMed]

53. Thaler, I.; Weiner, Z.; Itskovitz, J. Systolic or diastolic notch in uterine artery blood flow velocity waveforms in hypertensive pregnant patients: Relationship to outcome. Obstet. Gynecol. 1992, 80, 277-282. [PubMed]

54. Park, Y.W.; Cho, J.S.; Kim, H.S.; Kim, J.S.; Song, C.H. The clinical implications of early diastolic notch in third trimester Doppler waveform analysis of the uterine artery. J. Ultrasound Med. 1996, 15, 47-51. [CrossRef] [PubMed]

55. Livak, K.J.; Schmittgen, T.D. Analysis of relative gene expression data using real-time quantitative PCR and the $2^{-\Delta \Delta C T}$ method. Methods 2001, 25, 402-408. [CrossRef] [PubMed]

(C) 2019 by the authors. Licensee MDPI, Basel, Switzerland. This article is an open access article distributed under the terms and conditions of the Creative Commons Attribution (CC BY) license (http://creativecommons.org/licenses/by/4.0/). 